\title{
A Language Teaching Policy for Adult ESL
}

Tara Goldstein

Creating a curriculum plan for a language course is a complex undertaking which involves making a number of important decisions. To ensure they are making appropriate decisions, language teachers designing curriculum for their students need to develop a language teaching policy. Focusing on decisions that must be made in regard to content, objectives, treatment and evaluation, the following article suggests a language teaching policy for Adult ESL.

Today language teachers play a stronger, more direct role in planning curriculum and putting it into practice than ever before. The recent rapid growth of continuing education programs designed to address the language needs of adult learners had produced a large group of language teachers who assume total responsibility for the design of the course they have been hired to teach. This responsibility not only involves selecting subject matter or content, but selecting and developing appropriate course materials and evaluation procedures as well.

Creating a curriculum plan is a complex undertaking which involves making a number of important decisions. To ensure they are making appropriate decisions, language teachers designing curriculum for their students need to develop a language teaching policy. In their book Curriculum Planning for the Classroom, Connelly, Dukacz and Quinlan (1980) suggest that curriculum planning, in fact, planning of any kind, requires an understanding of what is and is not possible given one's own strengths, limitations, beliefs and values. Such understanding can evolve from reflecting on personal practical experience and from studying what others have said about language learning and teaching. To formulate and crystallize their own views and make use of others' thinking, teachers need a framework they can use to analyse the practice of language teaching as they know it.

Such a framework has been proposed by Stern (1983a; Figure 1) who views language teaching analysis as a three-level operation.

Beginning at the top of the model, analysis at the behavioural or surface level involves scrutiny of the teaching and learning activities that are planned for a particular group of students. These activities are considered 


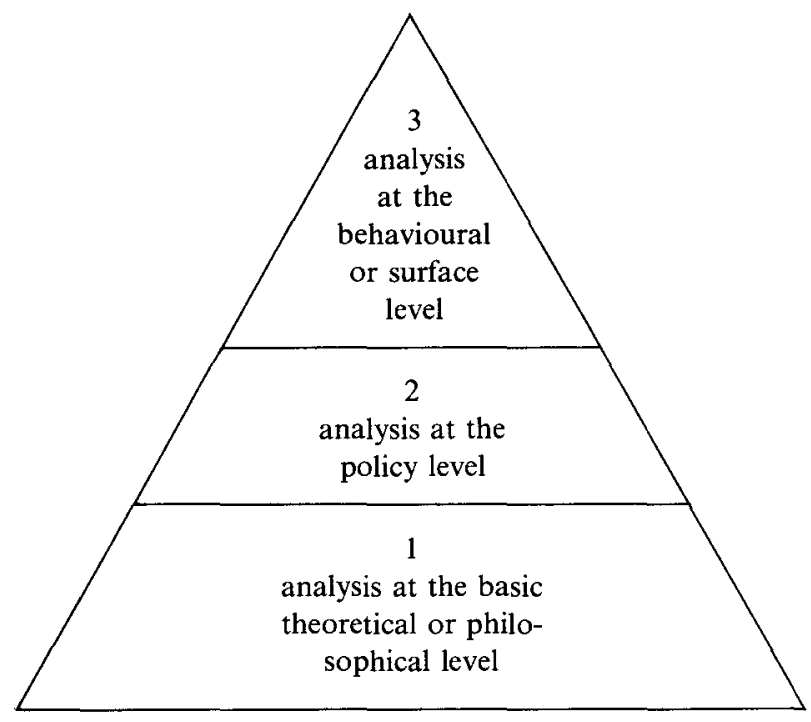

Figure 1. Language Teaching Analysis (Adapted from Stern, 1983a:6)

to be a reflection of earlier decisions made at the policy level. Thus, it is at this second level that self-examination becomes so important: if we do not consciously and critically examine the assumptions about language teaching and learning that are implicitly reflected in the activities we choose for our students, we run the risk of teaching language and designing curriculum in an haphazard "hit and miss" fashion. Teachers know when a particular activity has been successful or not; we know when our students have been able to produce successfully a linguistic pattern or have been able to use language creatively. Understanding what language teaching policy options we have exercised in carrying out an activity allows us to continue choosing such options if they are successful or try different options if they are not. Consciously or unconsciously, we make second level policy decisions in regard to content, objectives, treatment or procedures and evaluation. These decisions reflect our ideas on the nature of language, language learning, language teaching and society. For example, if the purpose of a particular activity is to practice forms of the verb "to be" with substitution drills, we have made the following decisions and assumptions: we have decided it is important that the content of our course include a grammatical component and that our students develop proficiency in producing structural patterns orally. These decisions are based on the assumptions that language is described in terms of form and 
that language ability is the product of practice and "overlearning." According to Stern (1983a), the more clearly teachers can evaluate the assumptions and decisions underlying the activities they choose or design for their students, the more effective their language teaching policy will be.

To summarize, developing a language teaching policy first involves examining and evaluating theoretical literature and research for what others think and have learned about the nature of language, language learning and language teaching. This examination and evaluation allows us to formulate our own personal theories which form the basis for making enlightened decisions about the content, objectives, procedures and evaluation of our language classes.

\section{DECISIONS ON CONTENT AND OBJECTIVES}

Stern's (1983a) framework identifies four content categories and four sets of objectives that can claim equal attention for serious curriculum development. These have been cross-tabulated and prioritized as illustrated in Figure 2.

\begin{tabular}{|c|c|c|c|c|}
\hline \multirow[t]{2}{*}{ Content } & \multicolumn{4}{|c|}{ Objectives } \\
\hline & Proficiency & Knowledge & Affect & Transfer \\
\hline \multicolumn{5}{|l|}{ Language } \\
\hline \multicolumn{5}{|l|}{ Culture } \\
\hline \multicolumn{5}{|c|}{$\begin{array}{l}\text { Communicative } \\
\text { Activities }\end{array}$} \\
\hline $\begin{array}{l}\text { General } \\
\text { Language } \\
\text { Education }\end{array}$ & & & & \\
\hline
\end{tabular}

KEY: $\quad$ Suggested major emphasis

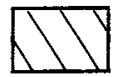

Suggested minor emphasis

Figure 2. Example of the interaction between content and objectives in a foreign language curriculum (Adapted from Stern 1983a:10) 
Since it is impossible to pursue all objectives and content categories simultaneously or to the same extent, it is necessary to identify and justify which cells will be emphasized in a particular situation. As seen above, Stern suggests that language teaching place a major emphasis on the proficiency objective when planning the language and communicative activities syllabus; the knowledge objective when developing the culture syllabus; and the transfer objective when creating the general language syllabus. The word syllabus simply refers to the description of the content under each of the four categories.

Briefly, the language syllabus is composed of a phonology, grammar, vocabulary and discourse component. Emphasizing a proficiency objective in this syllabus reflects a decision to help students develop various linguistic and communicative aspects of competence: phonological, grammatical, lexical, semantic and sociolinguistic. Teaching and learning activities in a second language program then, should provide pronunciation practice, grammatical practice, an opportunity to develop passive and active vocabulary and the opportunity to practise language items specific to a given role, situation, or function.

While language activities focus on the target language itself as an object of study and practice, the communicative syllabus involves students in experiential activities which provide opportunities for authentic communication. Emphasizing proficiency in this syllabus reflects the decision to assist students in using language creatively and developing what Canale and Swain (1980) call strategic competence-the ability to cope with communication breakdown.

The culture syllabus provides an introduction to the sociocultural context of the target language. Stern's emphasis on the knowledge objective in this syllabus reflects a decision to provide students with a conceptual knowledge of social and cultural facts.

Finally, the general language education syllabus is designed to develop a general awareness of language and language learning as well as knowledge about other languages and countries. Emphasizing the transfer objective in this syllabus reflects a decision to help students go beyond the language being taught, and acquire knowledge about learning, language, culture and society in general.

Stern's $(1983 \mathrm{~b}, 1983 \mathrm{c})$ rationale for the decisions he makes in regard to content and objectives is based on several assumptions. One assumption is that it is important to combine analytic and non-analytic approaches to language teaching; that is, it is important to focus on the study and practice of language itself (in terms of both formal and discourse features of language) and it is important to involve the learner in natural communication as well. A second assumption is that culture and language are 
inseparably intertwined and that a new language isn't really learned until the learner knows what cultural meaning a native speaker of the language attaches to the words and phrases he uses. Lastly, Stern assumes that language learning should contribute to the student's global education by fostering an awareness of language, culture, and society in general.

In analysing the specific situation of teaching ESL to adult learners who have emigrated to Canada, it seems justifiable to interpret Stern's framework as shown in Figure 3.

\begin{tabular}{|l|l|c|c|c|}
\hline Content & \multicolumn{3}{c|}{ Objectives } \\
\hline & Proficiency & Knowledge & Affect & Transfer \\
\hline Language & & & \\
\hline Culture \\
Activities
\end{tabular}

KEY: Stern's (1983a) suggested major emphasis

Additional emphasis for adult ESL learners

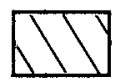

Suggested minor emphasis

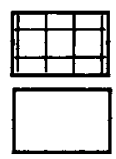

Figure 3. ESL for Adult Learners

In addition to adopting the sound assumptions and decisions Stern makes in regard to language teaching content and objectives, adult ESL teachers also need to recognize the importance of the affect objective when developing language, culture and communicative activity syllabuses. Larson and Smalley (1972) have linked effective language learning with the extent to which the adult learner becomes part of the community speaking the target language. Unfortunately, as Elson (1983) points out, that community is not always particularly welcoming to the newcomer. In difficult economic times, there is often a feeling that immigrants or refugees are threatening to "take jobs away from Canadians." Differences 
in dress and lifestyle also cause negative reactions in the receiving community. In the face of this, it is not unusual if the adult learner's enthusiasm for mastering the language of the community is somewhat diminished. As well, the immigrant or refugee may also suffer from a dramatic drop in status and self-image. The resulting self-doubt and anxiety can take away from some of the energy and concentration needed for effective language learning and reduce the learner's willingness to see the learning process positively. Consequently, the affect objectives of encouraging learners to develop an appropriate attitude toward the second language and second language culture and value contact with the second language community are an essential component of the adult ESL curriculum.

It is also suggested that a proficiency objective be added to the culture syllabus of an adult ESL program; to participate fully and grow in the second language community, students need to develop sociocultural competence, i.e., a performative knowledge of relevant cultural patterns or as Seelye (1984) puts it, the ability to demonstrate how people conventionally act in both common and crisis situations in the target culture.

In light of the additional objectives that need to be adopted for teaching adult ESL learners, it is reasonable to suggest limiting the scope of Stern's general language education syllabus to simply developing an awareness of how language is learnt. While it is very important for adult ESL learners to learn how to continue to learn about the target language outside the school situation so they may take advantage of the second language environment, it can be argued it is not as important for them to develop an awareness of language, culture and society in general. However, recently, there has been a move towards developing an intercultural education component into the adult ESL curriculum. ${ }^{1}$ Believing that many incidents of miscommunication are not only due to limited language proficiency, but to the cultural assumptions individuals make about each other, proponents of this approach feel it is extremely important to develop intercultural communication skills among adult ESL students. The value of adding such a component to a general language syllabus is difficult to assess as language teaching professionals are only beginning to explore the role intercultural communication plays in our work.

\section{DECISIONS ON TREATMENT/PROCEDURES}

Stern (1983a) classifies the main procedures or instructional options into three broad categories: teaching strategies, timing strategies and social or interpersonal strategies. He uses the word "strategies" because it denotes a broader concept under which a large number of techniques and 
activities can be subsumed: strategies are policy decisions which influence the type of techniques and activities we bring into the classroom.

\section{Teaching Strategies}

Decisions on teaching strategies are based on the assumptions we hold on three crucial issues in language learning: the L1-L2 connection, the code-communication dilemma and the explicit-implicit option.

The L1-L2 connection concerns the use or non-use of the student's first language in second language learning. Techniques which remain entirely within the second language are called intralingual or intracultural. Those which make use of the first language and native culture are called crosslingual or crosscultural. Adult ESL instructors who often have heterogeneous classes, are not always able to use crosslingual or crosscultural techniques and activities without relying on the individual expertise of their students. While some students have a great deal of awareness of how their language functions or of what values and beliefs are implicit in their culture, others do not. Unless the instructor can be sure that the information $\mathrm{s} /$ he receives from students is not misleading, it is unwise to adopt crosslingual or crosscultural techniques.

The code-communication dilemma refers to the possibility of treating the target language and culture as codes and thus as objects of study or practice or as something to experience subjectively through participation in communicative activities and personal contact. As previously discussed, it is important for adult ESL students to have the opportunity to become involved in both analytic and non-analytic activities.

The explicit-implicit option relates to choosing techniques which encourage the learner to use a cognitive or reasoning approach or adopting techniques which encourage students to "acquire" (Krashen 1981, 1982) language intuitively. Adult learners possess cognitive processes which enable them to make conscious generalizations and see relationships between things. In light of this ability, it is justifiable to emphasize the explicit option - particularly if the learner has some personal contact with the second language community and opportunities to "acquire" language outside the classroom.

\section{Timing and Social or Interpersonal Strategies}

The selection of timing strategies (in terms of determining the total amount of time available for language instruction and the distribution of that time) is almost always beyond the control of the adult ESL teachercurriculum designer. Likewise, the size and composition of language learning groups are usually administrative decisions. However, one social 
dimension in which the adult ESL instructor and course designer can and should exercise a personal philosophy and policy is that of balancing teacher-directedness and learner-initiated approaches through grouping and individualization.

Adults have a desire to be self-directing, to make choices which relate to their specific needs and abilities. As Knowles (1970) has noted, the child "becomes an adult psychologically at the point at which his concept of himself changes from one of dependency to one of autonomy." Given this desire to be able to control the circumstances of their lives, it follows that the most appropriate learning environment for the adult ESL learner is one that is "learner-centred." In a learner-centred class, the teacher is regarded as a resource person or guide who helps the learners to select activities that are relevant to their language needs and general concerns or interests. Appropriate adult ESL curriculum then, should generally provide ample opportunity for individual and small group work so students can develop their language skills in ways that are meaningful and helpful to them. At the same time, it is important to note that some adult learners only feel comfortable when there is a very high level of teacher control over what happens in the classroom. Balancing between providing considerable direction and encouraging learners to learn on their own and from each other calls for sensitivity to the ways individual students feel most comfortable learning and the flexibility to shift from teacher-student to student-student activities.

\section{DECISIONS ON EVALUATION}

The last area of policy decisions concerns evaluation. Stern (1983a) suggests the following possibilities:

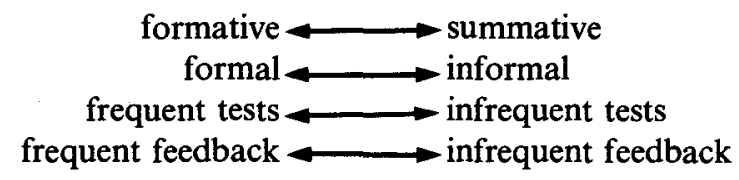

According to Bloom et. al. (1971), formative evaluation refers to the assessment of progress during the learning process. Summative evaluation is the assessment of student achievement at the end of a course; it is designed to evaluate whether the student has reached the goals envisaged by the curriculum. Both types of evaluation have a role to play in the adult ESL language program. As Elson (1983) points out, while classroom teachers often feel they "know" if students are accomplishing the goals of the course or not, it must be recognized that all members in the classroom - students and teachers alike - are liable to be subjective in 
making assessments as to how effective the language learning-teaching process has been. Formative evaluation can give instructors a reasonably objective idea of what students have mastered before moving on to new work. As well, it may indicate a weakness which has gone unnoticed. For the student, formative evaluation can give a more objective assessment of progress than a sympathetic teacher. Summative evaluation is important in regard to the assessment of the overall effectiveness of a curriculum and the policy options that have been selected to develop it.

In deciding upon the use of formal or informal testing techniques, it is important to consider the limitations to what a test can measure in the realm of communication. As Fougere (1983) points out, most formal testing only measures the students' ability to recognize or manipulate certain surface structures. It is also important to remember that testing can evoke apprehension in many learners. It may be reasonable then, to conclude that there is no real benefit to be had from using formal tests and that useful results can be obtained informally during the regular work of the class by assessing oral or written exercises and activities involving communicative exchanges. However, there are legitimate reasons for exposing students to a formal test format; for example, some students may encounter similar tests later on in their education careers and need practice in formal test taking. As well, whatever the value of testing might be for the teacher or learner, frequently students require some statement of language ability for practical external purposes such as admission to an academic program.

Determining the frequency of testing clearly depends on how important the evaluation of progress is to a particular group of students. Informal testing which takes place on a daily basis may provide students with sufficient information on their progress. For those students who believe regular testing is an indication that serious teaching is taking place however, frequent formal testing may be in order.

Related to the issue of determining the frequency of tests is the issue of determining the frequency of feedback or error correction. Rivers (1981) points out that psychological experimentation has shown that people are more likely to continue a conversation when other people agree than when they disagree. She goes on to say that in many societies, cultural patterns have conditioned people to keep their ideas to themselves if expressing them could cause unpleasantness and embarrassment for themselves or for the people with whom they are conversing. Thus, the student who is continually corrected by the teacher may withdraw into silence. Continual correction in areas where the students really know what should be said, especially when an instructor jumps in before the students have had time to correct themselves, can be very irritating. In 
light of these observations, many language teaching professionals feel that only mistakes which hinder comprehension or which prevent the conveying of intended meaning should be corrected. Consistent communication errors within a particular group may be discussed with the whole class as part of a review session. Others feel that if a linguistically incorrect utterance is rewarded globally because of its communicative value, incorrect elements or misapplied rules are being learned, as what is incorrect is being positively reinforced along with the larger message. Clearly the challenge in developing policy concerning error correction is finding a way to create an atmosphere in which the students will want to talk, but not one in which they will want to talk while completely disregarding accuracy. In establishing an error correction policy for adult ESL learners, it is helpful to return to the policies taken in terms of objectives. The decision to establish affective objectives in the language and communicative syllabuses points to the advisibility of generally adopting an encouraging rather than a correcting attitude. Yet, the fact that a proficiency objective has also been set in the language syllabus indicates that linguistic correction is important. It is suggested that during activities which focus exclusively on the study and practice of language itself, linguistic errors should be corrected as tactfully as possible. During activities which involve students in natural communication, only those errors which inhibit communication should be addressed as expression of personal meaning in a new language depends on positive feedback.

In conclusion, it is clear that an effective language teacher/curriculum planner is one who develops a personal language teaching policy. As Elson (1983) points out, it is important to emphasize that such a policy is not something we work out at some point and which then remains fixed for the duration of our careers. Rather, it is an illustration of an ongoing analysis of our strengths, weaknesses, sensitivity to students, and the circumstances under which learning is taking place. New developments in language teaching and learning should always be of interest to us for what they might contribute to our language teaching policy and thus, to our effectiveness as teachers and curriculum designers.

\section{REFERENCES}

Bloom, B., Hastings, J.L. and Madaus, G. (eds.) 1971. Summative Evaluation of Student Learning. New York: McGraw-Hill.

Canale, M. and Swain, M. 1980. "Theoretical bases of communicative approaches to second language teaching and testing." Applied Linguistics 1:1-47.

Elson, N. (ed.) 1983. "Teaching English as a Second Language to Adults: Methodology." TESL Talk, vol. 14, nos. $1 \& 2$. 
Fougere, Gloria, 1983. "Assessing Student Performance." TESL Talk, vol. 14, nos. 1 and 2.

Knowles, M. 1970. The Modern Practice of Adult Education. New York: Association Press.

Krashen, S.D. 1981. Second Language Acquisition and Second Language Learning. Oxford: Pergamon.

Krashen, S.D. 1982. Principles and Practice in Second Language Acquisition. New York: Pergamon Press.

Larson, D.N. and Smalley, W.A. 1972. Becoming Bilingual: A Guide to Language Learning. New Canaan, Conn.: Practical Anthropology.

Rivers, W.M. 1981. Teaching Foreign-Language Skills. Second edition. Chicago: University of Chicago Press.

Seelye, H.N. 1984. Teaching Culture: Strategies for Foreign Language Educators. Skokie, Ill.: National Textbook Company and ACTFL.

Stern, H.H. 1983a. "Seeing the Wood AND the Trees: Some Thoughts on Language Teaching Analysis," in M.Heid (ed.) Kommunikation im Klassenzimmer: Protokoll eines Werkstattgesprachs des Goethe House New York Im Septermber 1982. New York jand Munich: Goethe House, New York Goethe-Institut Munchen, pp. 319-44.

Stern, H.H. 1983b. Fundamental Concepts of Language Teaching. Oxford: Oxford University Press.

Stern, H.H. 1983c. "Toward a Multidimensional Foreign Language Curriculum," in R.G. Mead (ed.) Foreign Languages: Key Links in the Chain of Learning. Middlebury, VT.: Northeast Conference 1983, 120-146.

\section{THE AUTHOR}

Tara Goldstein has been teaching Adult ESL for five years. Originally from Montreal, she has designed and taught general ESL, composition, and ESP courses for Francophone students at the University of Montreal, the University of Manitoba and Dawson College. She has a M.A.T.E.S.L. degree from St. Michaeal's College in Winooski, Vermont and is working towards a Ph.D. in second language curriculum design at O.I.S.E. She is particularly interested in the sociocultural component of syllabus design. In addition to her studies, Ms. Goldstein is currently teaching workplace ESL classes for the Toronto Board of Education. 